УДК 130.31

DOI: $10.17223 / 1998863 X / 39 / 19$

\title{
А.М. Хамидулин
}

\section{С.Л. ФРАНК: СОЦИАЛЬНОЕ ИЗМЕРЕНИЕ МИСТИЧЕСКОГО}

Рассматривается философское учение С.Л. Франка об устройстве общества с точки зрения философского мистицизма. Анализируется логический путь, который проходит мысль С.Л. Франка от осознания индивидуального "Я» до сознания глубинного метафизического единства общества. Социально-философское учение С.Л. Франка рассматривается в контексте современных социальных и философских учений, исследующих подлинное устройство общественной жизни.

Ключевые слова: С.Л. Франк, мистицизм, соборность, сочиология, философия.

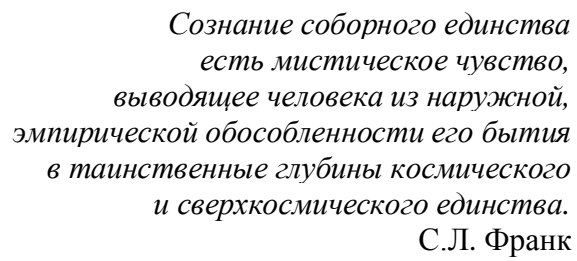

Категория «мистического» имеет множество определений. В изучении этого явления существуют разнообразные подходы. Феномен мистических переживаний исследуется широким спектром смежных наук, так или иначе затрагивающих деятельность человеческого сознания, - это такие науки, как религиоведение, философия, лингвистика, психология, нейрофизиология, когнитивистика. «Мистика» является той сферой человеческой жизни, в которой мы не найдем однозначных определений своего содержания, в силу такой специфики каждый исследователь феномена «мистического» использует ту интерпретацию, которая представляется ему наиболее адекватно отражающей реальность изучаемого явления. Сложность анализа области мистического является причиной, позволяющей употреблять слово «мистика» и использовать свой оригинальный подход в изучении этого явления каждым ученым.

Одним из первых исследователей, который попытался описать мистический опыт, имеющийся во всех религиях, как универсальный, был немецкий теолог и философ Ф. Шлейермахер. Согласно его позиции, которую можно поместить в основании изучения мистических переживаний, религия как таковая представляет собой скорее не область или, по крайней мере, не только область нравственного поведения человека и богословских исследований теологов. Религия - это, прежде всего, область практики человеческой жизни, эта сфера чувств, в конечном счете «...истинная религия - это чувство и вкус бесконечности» [1. С. 77].

Весомой по своему значению является деятельность известного исследователя религиозного опыта, предпринятая американским психологом и фило- 
софом У. Джеймсом [2]. Он выделил четыре фундаментальных качества, свойственных мистическим переживаниям:

- Неизъяснимость - такие события предельно отличаются от привычных нам и поэтому с трудом находят свое описание с помощью привычного языка.

- Абстрактность/Духовность/Интуитивность - опыт переживания сверхъестественного дает реальное знание в виде откровения о существовании идеального мира и ориентирован на целостное восприятие Универсума.

- Кратковременность - эти события продолжаются недолго по психологическому времени субъекта восприятия.

- Бездеятельность воли - человек, имеющий опыт столкновения с трансцендентным, воспринимает его без возможности ответного воздействия (манипулирования) на источник такого откровения, хотя вызываться такой опыт может с помощью волевых усилий; человек ощущает себя как бы «захваченным», чем-то бесконечно большим, чем он сам.

Подход к социальному измерению мистического в философии С.Л. Франка начинается с его рефлексии о трансцендировании человека вовне во взаимоотношения между «Я» и Другим - «Ты» (т.е. в этом рассуждении С.Л. Франк идет от социального к тому, что можно назвать мистическим). Во встрече человеческого «Я» с «Ты», собственно, и происходит «актуализация непосредственного самобытия, именно его раскрытие и развитие в «Я»...» [3. С. 348], иными словами, речь идет о взаимной обращенности друг на друга «Я» и другого сознания, другой души как необходимости встречи с Другим, которая только и позволяет определиться моему «Я» как чему-то единственному для меня и поэтому уникальному. Для реализации этой встречи необходимы, с одной стороны, выход «Я» за пределы меня самого, а с другой - обращение на меня «Ты», как своего рода откровение. При этом, несмотря на всю очевидную явленность и непосредственную открытость «Ты» по отношению к «Я», этот самый Другой остается по существу загадочной реальностью, чьей содержательной характеристикой для нас является его принципиальная непостижимость. Однако именно в этом откровении-переживании «Ты» «содержится зерно подлинного опыта о реальности» [3. С. 361]. С.Л. Франк говорит о встрече «Ты» с «Я» как особом «месте», в котором для нас - помимо осознания своего «Я» и «Ты» как Другого - открывается особая форма реальности, именуемая «Мы». Эта новая реальность обнаруживается, согласно логике русского философа, через осознание укорененности бытия моего «Я» в неком «царстве бытия-для-себя», которое можно представить в форме «...взаимосвязанной полицентричной системы, - в форме царства «духов», или конкретных носителей «непосредственного самобытия» ...» [3. С. 358]. В конечном итоге само бытие моего «Я» представляется не чем иным, как «его укорененностью в бытии «мы»» [3. С. 358] как в тотальном всеединстве подлинно общественного бытия.

Что же представляет собой эта особая форма бытия «Мы»? Будучи полицентричным явлением, содержащим в себе все множество «Я» в их взаимоотношении «Я - Вы», эта реальность предстает перед нами как единство при раздельности, основанное на взаимопроникновении реальности одного в другого, при сохранении их суверенной инаковости: «Сама реальность 
«другого» - само «ты» - проникает в меня; само «ты» есть для меня, переживается мною, открывается мне внутри меня - хотя и как реальность, внешняя по отношению ко мне» [3. С. 371]. Открытие этой реальности духовного бытия возможно как при трансцендировании вовне, так и трансцендировании вовнуть, вглубь, при котором человек достигает своей родины, обретает истинную почву и пускает в ней корни. «Мы» переживается непосредственно как то, что есть во мне, как первичная основа всякого «Я», при этом окружающее каждого из людей внешнее общество людей является лишь внешним отображением метафизического и мистического «Мы». Однако даже в этом видимом обнаружении всеединства «Мы» в виде государства, закона, семьи, общественного мнения перед нами приоткрывается мистическая реальность, которая наличествует как факт мироустройства и независима от ее «религиозно-этической оценки» [3. С. 383]. Для иллюстрации своей мысли о существе этого истинного «Мы» С.Л. Франк вспоминает учение Гераклита о взаимосвязанности частных сознаний друг другу через причастность пронизывающему их Логосу; учение стоиков о космосе как «государстве богов и людей»; принадлежащее Плотину сравнение людей с листьями дерева, видимо разобщенных, но невидимо питаемых общим соком, и, наконец, христианское учение, выраженное ап. Павлом о Церкви как живом теле Христовом. Таким путем С.Л. Франк приходит к убеждению в том, что истинная онтология возможна лишь в форме «социоморфизма» [3. С. 380]. При этом С.Л. Франк не признает наличия единого субъекта такого соборного сознания «Мы», но считает, что духовное единство множества человеческих «я» выражается во внутренней духовной связи сознаний всех людей, и называет это «многоединством» [4. С. 45].

Представляется интересным продемонстрировать близкие С.Л. Франку размышления о высоком значении совместного бытия «Мы» в социологической и философской мысли. При философском анализе бытия человека как бытия-с-другим обращает на себя внимание особый элемент всеобщности, феномен интерсубъективности ${ }^{1}$, который имеет безусловное значение также и в реализации языка в качестве речи-общения ${ }^{2}$, которая также имеет направленность к Другому. Как замечает М. Мерло-Понти, «языковой и интерсубъектный мир не удивляет нас, мы не отличаем его от самого мира, и мы размышляем именно внутри уже проговоренного и говорящего мира» [5. С. 240].

Так, например, Г.В.Ф. Гегель, называя язык произведением мысли, считает, что посредством языка всегда выражаются только всеобщие понятия, и даже когда мы говорим о своем «я», мы хоть и подразумеваем конкретного себя, отличного от других, но не менее само это произнесенное «я» есть «само по себе всеобщее, и общность есть также одна из форм всеобщности, но

\footnotetext{
${ }^{1}$ Со стороны так называемой социологии повседневности П. Бергер и Т. Лукман в совместном труде «Социальное конструирование реальности» по этому поводу заявляют: «Реальность повседневной жизни представляется мне как интерсубъективный мир, который я разделяю с другими людьми» (Бергер П., Лукман Т. Социальное конструирование реальности. М., 1995. С. 43).

${ }^{2}$ Как на то указывает Т.Ю. Быстова: «Общение - процесс, приводящий к формированию некого единого пространства, где существуют не только два собеседника в отдельности, но и некая общность, сформированная из «общих точек» и смыслов субъектов» (Быстров Т.Ю. Повседневность как пространство коммуникаций: методологический аспект // Приволжский научный вестник №2 (2). 2011. C. 110.).
} 
она лишь внешняя ее форма» [6. С. 114]. Рассматривая всеобщность, он замечает, что всеобщее не дано нам в непосредственном ощущении, но «существует лишь для духа» [4. С. 118]. И исходя из принадлежности к бытию «меня», Другого и Бога, а также ощущения и восприятия всего окружающего предметного мира посредством эмпатии и образности в «моем» сознании, можно говорить о межличностном пространстве, которое явно предшествует «мне» историческому. При мистическом же переживании личностного характера подобный уровень интерсубъективности выходит на новый качественный уровень. В православном богословии отношения внутри Св. Троицы понимаются как таинственное личностное общение. Получается, что сфера интерсубъективности не только имеет богословское значение, т.е. является важным моментом внутреннего самобытия Бога-Троицы, но и обладает онтологическим статусом. А, следовательно, по отношению к тварному миру сфера внутрибожеских отношений между лицами Св. Троицы предваряет и предопределяет появление человеческого сообщества со своей внутренней интерсубъективностью.

У современного французского философа Ж.-Л. Нанси можно обнаружить интересные размышления о таком «бытие-вместе». Ж.-Л. Нанси считает, что бытие единично и множественно одновременно, и это свойство является конститутивной особенностью бытия, оно «маркирует одновременно абсолютную эквивалентность и открытую артикуляцию, которую невозможно замкнуть на некоторой идентичности» [7. С. 55]. Это свойство бытия, выражаемое философом в такой специфической форме, на деле означает, что сущностью бытия является как раз со-сущность или со-бытие, как бытие-со-многими, и в этой сущности самое это «со-», в свою очередь, следует понимать в качестве сущности. Здесь должно прозвучать ключевое слово самого Ж.-Л. Нанси: «Со-сущностность означает сущностное разделение сущностности, разделение в виде совокупности, если угодно. Что может быть выражено и таким образом: если бытие - это со-бытие, в со-бытии именно это вместе и создает бытие, а не прибавляется к нему» [7. С. 58]. Далее философ для иллюстрации своей мысли прибегает к примеру коллегиальности власти, при которой власть состоит не в чем-то внешнем или внутреннем по отношению к каждому ее члену, но заключается в самом принципе коллегиальности. Исходя из этого, Нанси говорит о необходимости переосмыслить всю прежнюю философскую экспозицию, ибо даже Хайдеггер, автор фундаментальной онтологии, начинает говорить о некой со-изначальности Mitsein (бытие вместе с кем-либо) лишь после того, как устанавливает изначальность Dasein (вотбытия), в то время как на первом месте стоит то самое вместе, которое является центром бытия. Поэтому единственный онтологически верный способ это говорить не от лица «меня» и не от лица Другого, ни от их совокупности, но говорить от лица «мы», сущность которого есть бытие вместе, одно-сдругим. Причем неверно было бы понимать такую философию в качестве некой региональной философии общества, позиция Нанси заключается в том, что онтология сама по себе изначально социальна до всякой человеческой индивидуальности и всеобщности, ибо все существующее детерминировано самой своей принадлежностью к бытию быть сущим одно-с-другим. В итоге, 
сама философия есть «мышление о со-бытии, и поэтому она сама также есть мышление-вместе как таковое» [7. С. 60].

Социолог и философ Альферд Шюц, применяя феноменологию Гуссереля к социальному анализу, уделяет значительное внимание теме интерсубъективности реальности: «Мир моей повседневной жизни никоим образом не является моим частным миром, но есть с самого начала общий интерсубъективный мир, который я разделяю с моими собратьями, мир, который переживают и интерпретируют, наряду со мной, другие люди; короче говоря, это мир, общий для всех нас» [8. С. 481-482]. А. Шюц обращает внимание на то, что Природа и Общество, с одной стороны, являются частными моментами личной биографии людей, а с другой - конституируют саму жизнь человека, и к ним люди вынуждены приспосабливаться. Природа и Общество по отношению к индивиду являются трансценденциями, ибо, с одной стороны, превосходят границы человеческого опыта, а с другой - люди приходят в мир уже существующего контекста Природы и Общества. Получается, что выход человека из сферы своей индивидуалистичной замкнутости в сферу социума или природы можно понимать как вариант трансцендирования (тем более, если речь идет о выходе в сферу мистического). Помимо этого, у австрийского философа можно обнаружить разработку идей множественных реальностей. Шюц считает, что в повседневной жизни человека внешний, чувственно-физический мир рабочих интерсубъективных операций является верховной реальностью по отношению к смысловым и символическим сферам. При этом под реальностью того или иного разряда мироздания следует понимать «связь с нашей эмоциональной и деятельной жизнью; реально все, что возбуждает и стимулирует наш интерес» [8. С. 510]. Из этой социологической концепции следует, что миры научного размышления, поэзии и искусства, религиозного опыта, так же как и миры игры, фантазий, сновидений, сумасшествия, обладают собственным внутренне непротиворечивым когнитивным стилем, но в то же время эти разные сферы не совместимы друг с другом, и переход между ними осуществляется посредством изменения напряженности и внимания нашего сознания, что ощущается субъективно как некий скачок, шок. Выражение смыслов, заключенных в эти сферы, крайне проблематичен, поскольку наш язык функционирует прежде всего в зоне рабочих операций верховной реальности, что заставляет профильные сферы (наука, искусство, религия) изобретать собственный специфический язык выражения. И, конечно, все эти сферы реальности - «конечные области смысла», как именует их А. Шюц, обладают своим особым «акцентом реальности» [9. С. 18-19].

Существует еще один оригинальный взгляд на топологию (меж-) личностного пространства, предложенный современным немецким мыслителем Петером Слотердайком в его фундаментальном проекте «сферологии». Так, Петер Слотердайк, опираясь на герменевтические наработки М. Хайдеггера, последовательно критикует устоявшееся представление об автономии человеческих индивидуумов и заявляет о существовании так называемых символических сфер, в которых люди оказываются связанными друг с другом на интуитивном уровне общего «кровоснабжения». Все люди включены в сфе- 
ры $^{1}$, это есть структура человеческих взаимоотношений, и даже когда человек в полной мере предстает индивидом, в нем все равно сохраняется в тайне парная структура устройства, причем первичной сферичной формой выступает именно пара. На поверхности таких сфер могут существовать несколько полюсов, в зависимости от включенности в сферу субъектов отношений, притом саму поверхность сферы, которую можно представлять наподобие мыльного пузыря в воздухе, образуют бесконечные меридианы межполюсных взаимодействий, влияющих друг на друга, вызывающих, отталкивающих, проникающих, поддерживающих. Эти взаимоотношения, устроенные на принципах сопричастности и сопроникновения, которые продолжают существовать даже сегодня под масками независимости и свободы. Речь идет об особого рода интимных видах общения, которых Б.В. Марков в сферологии Слотердайка выделяет несколько: сердечные, межличностные, магнетикогипнотические, материнские, братские, мессиански-пророческие. Тот же исследователь Б.В. Марков, замечает, что в данных межличностных отношениях существует общее, заключающееся в том, «что между их участниками отсутствует разделение на субъект и объект, конфронтация с предметами и, наоборот, имеет место включенность Я-полюса в ситуацию, интеграция его с окружением» [10. С. III]. Исходя из этого, по мысли Слотердайка, «нет никаких индивидов - есть только ди-виды: есть только люди как частицы или как полюса сфер» [11. С. 215]. Человек в такой картине мира представляется как «растворяющееся в пространстве существо, как психический полевой эффект» [11. С. 224]. В таком подходе сама реальность представляется существующей не в нашем сознании, а между ними, где человеческий «мозг по самой своей сущности входит в некую...коллективную систему» [10. С. 275] и человеческое сознание от рождения обладает способностью к некому экстатическому прорыву, позволяющему людям выйти за свои пределы с возможностью понимать других людей и конструировать себя. Сам Слотердайк, имея личный опыт жизни в общинах хиппи, указывает на возможность качественного повышения уровня (и его осознания) межличностной коммуникации в малых социальных группах, в которых солидарность ощущается всеми участниками как воздух ${ }^{2}$. Таким образом, Слотердайк открывает в своем творчестве мир с идеальным планом бытия, связующим звеном между конечным и бесконечным в котором играет сфера человеческого сознания.

С.Л. Франк в своем требовании подлинного осмысления общественной жизни критикует эмпирический подход людей, считающих общество лишь

\footnotetext{
1 Подобное представление дает нам основание вспомнить платоновский миф об идеальном человеке - андрогине, сочетающем в себе и мужские и женские метафизические признаки, сила которых была способна бросить вызов богам, так вот - их форма была как раз шаровидной (Пир, 1906), боги же раскололи это единство, и поэтому сейчас каждый из людей ищет свою «вторую половину».

2 Можно вспомнить эпизод из истории раннехристианских общин: «У множества же уверовавших было одно сердце и одна душа; и никто ничего из имения своего не называл своим, но все у них было общее» (Деян. 4:32). «Одно сердце и одна душа»- этот тот образ, который является образцом межличностной коммуникации для всех верующих. Следует обратить здесь внимание, что акцент поставлен именно на единение, а не на индивидуалистическую замкнутость, которая, по мысли Дж.П. Мануссакиса, есть не что иное, как идолопоклонство каждого-для-себя, явление демонической самозамкнутости на себе, принадлежность к аду (Мануссакис Дж.П. Бог после метафизики. Богословская эстетика. Киев, 2014. С. 62).
} 
совокупностью отдельных «конкретных» индивидуумов, не способных за единичным увидеть общее («за деревьями увидеть лес»), которое как раз и есть подлинно конкретное и истинное, в то время как «изолированно мыслимый индивид есть всего лишь абстракция» [4. С. 53]. В своем видении устройства общественной жизни С.Л. Франк выделяет два аспекта - временный и вневременный: «...с одной стороны, есть многообразие и беспрерывная изменчивость и, с другой стороны, есть непреходящее единство, объемлющее и пронизывающее всю эту изменчивость» [4. С. 28]. Так, русский философ исходит из, по сути, религиозного убеждения о существовании наряду с эмпирическими и онтологических вечных закономерностей [4. С. 35]. Причисляя себя к сторонникам так называемого универсализма в социальнофилософской мысли (и выступая против сингуляризма или социального атомизма), С.Л. Франк оказывается в одном лагере с Аристотелем, Платоном (для которого «общество есть “большой человек”, некая самостоятельная реальность, имеющая свою внутреннюю гармонию, особые законы своего развития» [4. С. 38]), христианским учением о Церкви как мистическом теле Христовом, идеями Жозефа де Местра, Бональда, О. Конта, Э. Берка, Спенсера и Дюркгейма. В то же время С.Л. Франк выделяет в общественной жизни два слоя - внутренний (связь «Я» с «Мы», внутренне-интуитивная слитость с бытием, то, что именуется соборностью) и внешний (противоборство многих «Я» и моего «Я», сфера внешне-телесного, рационально-предметного, то, что в строгом смысле именуется общественностью) [4. С. 54-55]. Делая акцент на внутреннее, подлинное устройство общественных отношений, С.Л. Франк ставит знак равенства между соборностью и религиозностью, понимая при этом религиозность как «чувство связи человеческой души с абсолютным началом и абсолютным Единством» [4. С. 59]. На этом основании русский мыслитель говорит о чувстве сопринадлежности отдельного «Я» целому, которое окружает личность человека не извне, но изнутри наполняет ее. Это есть «по своему существу именно мистическое религиозное чувство своей утвержденности в таинственных, охватывающих нашу личность глубинах бытия» [4. С. 59], делает вывод С.Л. Франк. В своем размышлении о метафизическом устройстве «Мы» С.Л. Франк приходит к чисто религиозному пониманию общественной жизни и считает, что в своей самой глубокой и чистой форме такое религиозное чувство соборности обнаруживает родство человека и Церкви как подлинного «Мы» с Богом как Нашим Отцом [12. С. 369].

В итоге мы имеем общность как особую форму бытия - «подлинное реальное единство, скрытое за множественностью отдельных индивидов» [4. C. 43], ту духовную глубину, в которой все едины с другими «в неком последнем единстве» [4. С. 53]. При этом проанализированная С.Л. Франком важность объединяющего момента в межличностном взаимодействии, которая предшествует всякому единичному человеческому «Я», обнаруживается и в современной социологической и философской мысли в качестве конституирующей особенности общественных отношений, что позволяет с новых позиций взглянуть на учение С.Л. Франка о соборности. На этом основании мы, с одной стороны, можем говорить о социальном измерении метафизики, указывая при этом на онтологические устройства мироздания (статический 
аспект данности, образ лестницы), а с другой стороны, как раз о социальном измерении мистического в философии С.Л. Франка, стремясь указать на динамический аспект (образ движущегося эскалатора), доступ человека к живой реальности, который может быть открыт и пережит каждым человеком как момент подлинного бытия «Мы». Таким образом, учение С.Л. Франка о соборности как подлинном устройстве общества можно рассматривать как учение о мистической глубинной области взаимодействия людей, через которую открывается перспектива взаимоотношения Общества и Абсолюта.

\section{Литература}

1. Шлейермахер Ф.Д. Речи о религии к образованным людям ее презирающим. Монологи. СПб., 1994.

2. Джеймс У. Многообразие религиозного опыта. М.: Наука, 1993.

3. Франк С.Л. Непостижимое / / Франк С.Л. Сочинения. М., 1990.

4. Франк С.Л. Духовные основы общества. М., 1992.

5. Мерло-Понти М. Феноменология восприятия. СПб., 1991.

6. Гегель Г.В.Ф. Энциклопедия философских наук. Т. 1: Наука логики. М.: Мысль, 1974.

7. Нанси Ж.-Л. О бытии единичном множественном // Бытие единичное множественное. Мн., 2004.

8. Шюи А. Избранное: Мир, светящийся смыслом. М., 2004.

9. Шюи А. О множественности реальности // Социологическое обозрение. 2003. Т. 3, № 2.

10. Слотердайк С. Сферы. Микросферология. Т. І: Пузыри. СПб., 2005. 2015.

11. Слотердайк П., Хайнрихс Г.-Ю. Солнце и смерть: Диалогические исследования. СПб.,

12. Франк С.Л. С нами Бог // Духовные основы общества. М., 1992.

Artem M. Khamidulin. Nizhny Novgorod Theological Seminary (Nizhny Novgorod, Russian Federation), Moscow Theological Academy (Moscow, Russian Federation).

E-mail: captain.nemo.2012@yandex.ru

DOI: $10.17223 / 1998863 \mathrm{X} / 39 / 19$

S.L. FRANK: THE SOCIAL DIMENSION OF THE MYSTICAL

Key words: S.L. Frank, mysticism, sobornost, sociology, philosophy.

The article considers the social philosophy of S.L. Frank from the point of view of mysticism. The phenomenon of mystical experiences is explored by a wide range of related sciences that in one way or another affect the activities of human consciousness - such sciences as religious studies, sociology, philosophy, linguistics, psychology, neurophysiology, cognitive science. "Mysticism" is that sphere of human life in which we do not find unambiguous definitions of its content, because of this specificity, every researcher of the phenomenon of "mystical" uses that interpretation that seems to him most adequately reflecting the reality of the phenomenon being studied. This reason opens up prospects for an interdisciplinary study of mysticism. A complex phenomenon in mysticism can be identified a number of aspects, one of which - social - and this article is devoted.

In the social philosophy of S.L. Frank, we discover the doctrine of a certain community "We" as a special form of being, which reveals to us a genuine unity, hiding behind the many private "I". At the same time, the analyzed S.L. Frankly, the importance of the unifying moment in interpersonal interaction, which precedes any single human "I", is revealed in modern sociological and philosophical thought as a constitutive feature of social relations, which allows us to look at the teachings of SL from a new angle. Frank about the conciliarity. On this basis, on the one hand, we can talk about the social dimension of metaphysics, indicating at the same time the ontological devices of the universe (the static aspect of the given, the image of the staircase), and on the other hand, just about the social dimension of the mystical in philosophy. Frank, trying to point to the dynamic aspect (the image of a moving escalator), a person's access to a living reality that can be discovered and experienced by every person as the moment of the true being "We". Thus, the teaching of S.L. Frank about the catholicity as the true structure of society, can be regarded as the teaching of the mystical deep field of human interaction, through which the perspective of the relationship between the Society and the Absolute opens. 


\section{References}

1. Schleimaher, F.D. (1994) Rechi o religii $k$ obrazovannym lyudyam ee prezirayushchim. Monologi [Speeches about religions to the educated people who despise it. Monologues]. St. Petersburg.

2. James, W. (1993) Mnogoobrazie religioznogo opyta [The Varieties of Religious Experience]. Translated from English by V.G.Malakhieva-Mirovich, M.B. Shik. Moscow: Nauka.

3. Frank, S.L. (1990) Sochineniya [Works]. Moscow: Pravda.

4. Frank, S.L. (1992) Dukhovnye osnovy obshchestva [The spiritual foundations of society]. Moscow: Respublika.

5. Merleau-Ponty, M. (1991) Fenomenologiya vospriyatiya [Phenomenology]. Translated from French by I.S. Vdovina, S.L. Fokin. St. Petersburg: Nauka.

6. Hegel, G.V. (1974) Entsiklopediya filosofskikh nauk [Encyclopedia of Philosophical Sciences]. Translated from German by B.A. Fokht. Vol. 1. Moscow: Mysl'.

7. Nancy, J.L. (2004) Bytie edinichnoe mnozhestvennoe [Being Singular Plural]. Translated from French by E. Furs. Minsk: Logvinov.

8. Schüts, A. (2004) Izbrannoe: Mir, svetyashchiysya smyslom [Selected: The world luminous with a sense]. Translated from German and English. Moscow: ROSSPEN.

9. Schüts, A. (2003) O mnozhestvennosti real'nosti [On the varieties of realities]. Sotsiologicheskoe obozrenie - Russian Sociological Review. 3(2).

10. Sloterdijk, S. (2005) Sfery. Mikrosferologiya [Sphere. Microspherology]. Vol. 1. Translated from German by K. Loshchevskiy. St. Petersburg.

11. Sloterdijk, P., Heinrich, G.-J. (2015) Solntse i smert': Dialogicheskie issledovaniya [Sun and Dead: Dialogical Studies]. Translated from German by A. Pretsev. St. Petersburg: I. Limbach.

12. Frank, S.L. (1992) Dukhovnye osnovy obshchestva [The Spiritual Aspects of The Society]. Moscow: Respublika. 